\title{
Carimbo: democratização e acessibilidade da arte impressa na prática arte-educativa
} Sello: democratización y accesibilidad de la arte impreso en la práctica arte-educativo Rubber Stamp: democratization and accessibility of printed art in art-education practice

\author{
Isabela De Vita Jaha \\ Universidade Estadual de Campinas, Instituto de Artes \\ isa.jaha@hotmail.com
}

\section{RESUMO}

A "oficina de carimbo: intervenção e artes gráficas", inicialmente realizada na cidade de Campinas, São Paulo, em outubro de 2019, apresenta como principal proposta mostrar aos participantes da oficina sobre o carimbo enquanto potência artística, visual, educativa e coletiva, sobretudo em intervenções artísticas e ações culturais. Para introduzir os alunos ao universo do carimbo, a oficina recebeu caráter teórico-prático, em que houve uma breve introdução sobre a história do carimbo através de referências visuais (fotografias e grafismos) de carimbos feitos ao redor do mundo, nos mais diversos períodos históricos, e em seguida os participantes puderam produzir seus próprios carimbos a partir de materiais e técnicas não-convencionais dessa linguagem. O carimbo é entendido nesta oficina artístico - educativa como uma forma de democratização da arte impressa e de outras manifestações artísticas, em que o carimbo se (trans)forma em poesia, mensagem, performance, intervenção, trabalho coletivo, ensinamento e aprendizado, além de ressignificar o carimbo como um dispositivo que apresenta potencialidades nas artes visuais e integradas, transmitindo novas poéticas e visualidades à esta técnica de arte impressa que fora marginalizada em diversos aspectos.

Palavras chave: Carimbo, Arte Impressa, Arte-educação, Potencialidade, Poética

\section{RESUMEN}

El "taller de sellos: intervención y artes gráficas", inicialmente celebrado en la ciudad Campinas, San Pablo, en octubre 2019, se presenta como su principal propuesta para mostrar a los participantes del taller sobre el sello como una potencialidad artística, visual, educativa y colectiva, especialmente en intervenciones artísticas y acciones culturales. Para presentar a los estudiantes el mundo de los sellos, el taller recibió un carácter teórico-práctico, en el que hubo una breve introducción a la historia de los sellos a través de referencias visuales (fotografías y gráficos) de sellos hechos en todo el mundo, en los períodos históricos más diversos, y después los participantes pudieron producir sus propios sellos a partir de materiales y técnicas no convencionales de producir sellos. El sello se entiende en este taller artístico - educativo como una forma de democratizar el arte impreso y otras manifestaciones artísticas, en el que el sello se (trans)forma en poesía, mensaje, actuación, intervención, trabajo colectivo, enseñanza y aprendizaje, además de renunciar al sello como un dispositivo que presenta potencialidades en las artes visuales e integradas, transmitiendo nuevas poéticas y visualidades a esta técnica de arte impreso que había sido marginado en aspectos variados.

Palabras clave: Sello, Arte Impreso, Arte-educación, Potencialidad, Poética 


\section{ABSTRACT}

The "stamp workshop: intervention and graphic arts", initially realized in Campinas, São Paulo, in October 2019, presents as the main proposal to show the workshop's students about the rubber stamp as an artistic, visual, educational, collective potency, mostly in artistic interventions and cultural actions. To introduce the students to the universe of stamps, the workshop received a theoric-practical feature, wherein had a brief introduction about the story of stamp through visual references, as pictures and graphics, of stamps made all over the world and in many historical periods, and then the students could produce their own stamps from non-conventional materials and techniques of this artistic language. The stamp is understood in this artistic-educational workshop as a democratization form of printed art and many others artistic expressions, wherein the stamp (trans)form itself in poetry, message, performance, intervention, collective work, teaching and learning, beyond reframing the stamps as a dispositive that shows potentialities in visual and integrated arts, sharing new poetics and visualities of this printed art technique, which has been marginalized in so many ways.

Keywords: Stamp, Printed Art, Art Education, Potentiality, Poetic

\section{Introdução}

A prática educativa não-escolar oferece desafios e perspectivas interessantes aos educadores, em que o espaço não institucionalizado se apresenta como um lugar de trocas mais flexíveis entre educador e aluno do que em ambientes escolarizados, principalmente em situações nos estilos ateliê e oficina, estilos e locais estes que proporcionam aprendizagens consideravelmente horizontais, menos hierárquicas e elitizadas. Nas artes visuais, a prática educativa ocorre positivamente em ambientes mais coletivos e que promovem a criatividade dos estudantes, onde arte se torna um campo visual de transmitir sentimentos, ideologias, causas, críticas e pensamentos, sejam eles pessoais ou sociais. A oficina, neste caso, é um espaço interpretado como um ambiente em busca da democratização da educação, arte e cultura, em que os ensinamentos são tratados de maneira bastante próxima aos participantes da oficina. Neste presente artigo, a oficina de carimbo: intervenção e artes gráficas surgiu como forma de promover a arte impressa de forma mais acessível, além de apresentar novas formas de produzir trabalhos artísticos a partir de novas técnicas e potencialidades que o carimbo pode oferecer; a arte impressa, muito associada à técnicas mais reconhecidas como xilogravura e serigrafia, possui diversas outras técnicas, dentre elas o carimbo, sendo o mais conhecido aquele produzido em borracha com um pequeno cabo de madeira. $\mathrm{O}$ carimbo, comumente associado à burocracias e materiais e escritórios e que fora marginalizado em diversas formas no universo da arte, foi apropriado por diversos artistas visuais brasileiros que estavam à procura de um sistema discreto e marginal de transmitir mensagens, além de expandir o campo artístico com novas manifestações artísticas. Ensinar e promover a arte do carimbo, como proposta desta presente oficina de carimbo, é uma maneira de retomar a história da arte a partir de outro olhar e de apresentar novas maneiras de produzir trabalhos artísticos, onde a poética da repetição e a necessidade da intervenção artística ressignificam novos caminhos da arte, sobretudo em situações cotidianas, onde carimbo se transforma como uma metamorfose de potencialidades e cria novas simbologias.

"O carimbo é, por definição, destinado à reprodução." (CARRIÓN, 1980, como citado em PORTO, 2016, p.22)

\section{O processo da prática}

A "oficina de carimbo: intervenção e artes gráficas" ocorreu pela primeira vez em outubro de 2019 na cidade de Campinas do Estado de São Paulo, com a quantidade inicial de 15 vagas, porém, a demanda pela oficina estava mais elevada que o esperado, então a quantidade de vagas elevou para 20. A oficina ocorreu dentro de uma sala de aula, ou seja, inicialmente as cadeiras e mesas estavam dispostas de forma expositiva, de forma que todos os alunos estivessem olhando em direção ao educador, porém a sala foi repensada e as mesas foram dispostas em formato de ferradura, de forma que o educador pudesse passear por todos os participantes da oficina e os participantes pudessem olhar em direção à lousa e à tela de projeção. Ao entrarem, os participantes e fotógrafos da oficina se depararam com o formato da sala não convencional, e se acomodaram em pequenos grupos, em que as pessoas já conhecidas entre si ficaram juntas durante o processo.

A oficina, que obteve caráter teórico-prático, teve início com uma aula expositiva sobre a história do carimbo ao redor do mundo, começando com sociedades pré-históricas e terminando com referências de artistas brasileiros durante a ditadura militar de 1964. Como base da oficina, foi utilizada 
uma tese de mestrado que apresenta diversas referências da história e estética do carimbo.

Para apresentar as referências históricas e apoiar a aula, foi utilizado um projetor que expôs uma apresentação de slides com diversas imagens que serviram não apenas como apoio, mas serviram de base para a aula. É relevante ressaltar a importância do recurso do projetor nesta oficina pelo fato da projeção ser uma tecnologia que promove mais agilidade durante uma aula expositiva, sendo que, no caso desta oficina, os slides propuseram uma referência visual sobre o que estava sendo dito. O recurso foi proveitoso, e os participantes da oficina associaram de forma muito mais rápida o que estava sendo dito sobre a história do carimbo. As imagens evidenciaram diferenças, semelhanças, materiais e suportes em cada produção de carimbo através do tempo.

Logo após a aula expositiva sobre referências desta forma de arte impressa, foi feito um pequeno intervalo e depois se iniciou o eixo prático da oficina: os participantes foram ensinados a produzir carimbos a partir da técnica da borracha escolar e da placa de e.v.a. Primeiro, foi ensinada a técnica do e.v.a; de maneira resumida, foi mostrado um passo-a-passo de como produzir a técnica e os alunos realizaram um processo de desenhar e cortar o e.v.a no desenho desejado, colar o desenho na placa de papelão e o cortar, entintar o carimbo recém-produzido e carimbar em algum suporte, principalmente em papel sulfite. Depois, com a técnica da borracha, os participantes aprenderam a esculpir a borracha escolar com estilete, formando um carimbo personalizado. A oficina teve duração de 4 horas e os alunos puderam ficar com suas produções.

A oficina além de um objetivo: poética e educação

\section{1 - Objetivos antes}

Quando a oficina estava se desenvolvendo, a ideia primordial dela era oferecer uma nova possibilidade do campo da arte impressa e plástica através de uma técnica que poderia ser fácil e rapidamente produzida com materiais escolares, comuns ao dia-a-dia; afinal, a borracha escolar, o estilete, a placa de e.v.a etc. são materiais de fácil acesso. Outro grande propósito foi desenvolver novas potencialidades inseridas nas artes, em que o carimbo pode integrar plástica com performance, happening, dança, poesia, entre outras linguagens artísticas.

Por fim, outro grande objetivo foi aproximar os artistas a produzir obras coletivas, em que a intervenção artística com carimbo poderia ser utilizada como mensagem, além de crítica social. A oficina enquanto prática arte-educativa exerceu um importante papel de tornar os alunos como protagonistas também, em contrapartida aos modelos tradicionais escolares onde o professor não exerce uma honesta troca com o aluno, onde o professor ensina e os alunos aprendem. Numa oficina, todos podem ensinar e todos podem aprender.

\section{2 - Objetivos durante}

Quando a oficina de fato começou, foram notados alguns pequenos desafios que acompanharam toda a oficina, como o de captar a atenção de todos os participantes e aplicar o conteúdo ao mesmo tempo. Durante o eixo teórico, os conteúdos foram sendo aplicados e os alunos estavam com algumas dúvidas, que logo foram atendidas. Algumas perguntas eram recorrentes, como o por quê do carimbo possuir um material específico, ou o por quê deles possuirem aqueles específicos desenhos. As dúvidas não incomodaram o decorrer da oficina, pelo contrário, elas acrescentaram a teoria com novas informações. Já o eixo prático obteve uma grande aceitação pois os participantes nunca tiveram contato com experiência parecida; os participantes realizaram seus carimbos personalizados com seus próprios estilos de desenhos e linhas de pesquisa (fig. 1). Alguns começaram a explorar o carimbo com materiais que eles mesmos levaram para acrescentar a experiência, como canetas coloridas; o suporte oferecido a eles foi o papel (fig.2), contudo alguns exploraram novos suportes, como a pele e o tecido de suas mochilas.

\section{3 - (trans)formações de um objetivo inicial}

Com a oficina finalizada, os artistas puderam levar suas produções para casa, e postumamente as produções foram postadas em suas redes sociais, além de outras produções feitas ao longo do tempo. Foi entendido que o objetivo inicial foi concluído: levar adiante a arte do carimbo enquanto arte impressa acessível e democrática; é interessante pensar sobre a mobilização que esta oficina obteve durante e depois dela, pois novos carimbos foram sendo feitos, e surgiu uma pequena corrente de ex-participantes ensinando seus colegas a produzirem carimbos da forma ensinada a eles. Com essas ações pós-oficina, foi possível compreender que a educação é sempre passada à frente, como uma forma de mobilizar uma corrente que só tende a aumentar. A oficina de carimbo teve como primeiro propósito democratizar o ensinamento da arte impressa; terminou com a democratização da educação. Todos se tornaram alunos, todos se tornaram professores.

\section{Considerações finais}

Através deste relato, é possível compreender que a educação é advinda de diversas linhas, direções e correntes, dentre elas a prática escolar e a não-escolar. A oficina, enquanto modelo não-escolar, se metamorfoseia em um espaço coletivo e colaborativo, onde a educação não apresenta hierarquias ou castas, mas representa a corrente do aprendizado. O oficineiro não obtém o papel apenas de 
Figura 1 - Participantes produzindo seus carimbos. Fonte: Luiza Schilling Lopes, 2019

Figura 2 - Gravando com carimbo de e.v.a. Fonte: Luiza Schilling Lopes, 2019
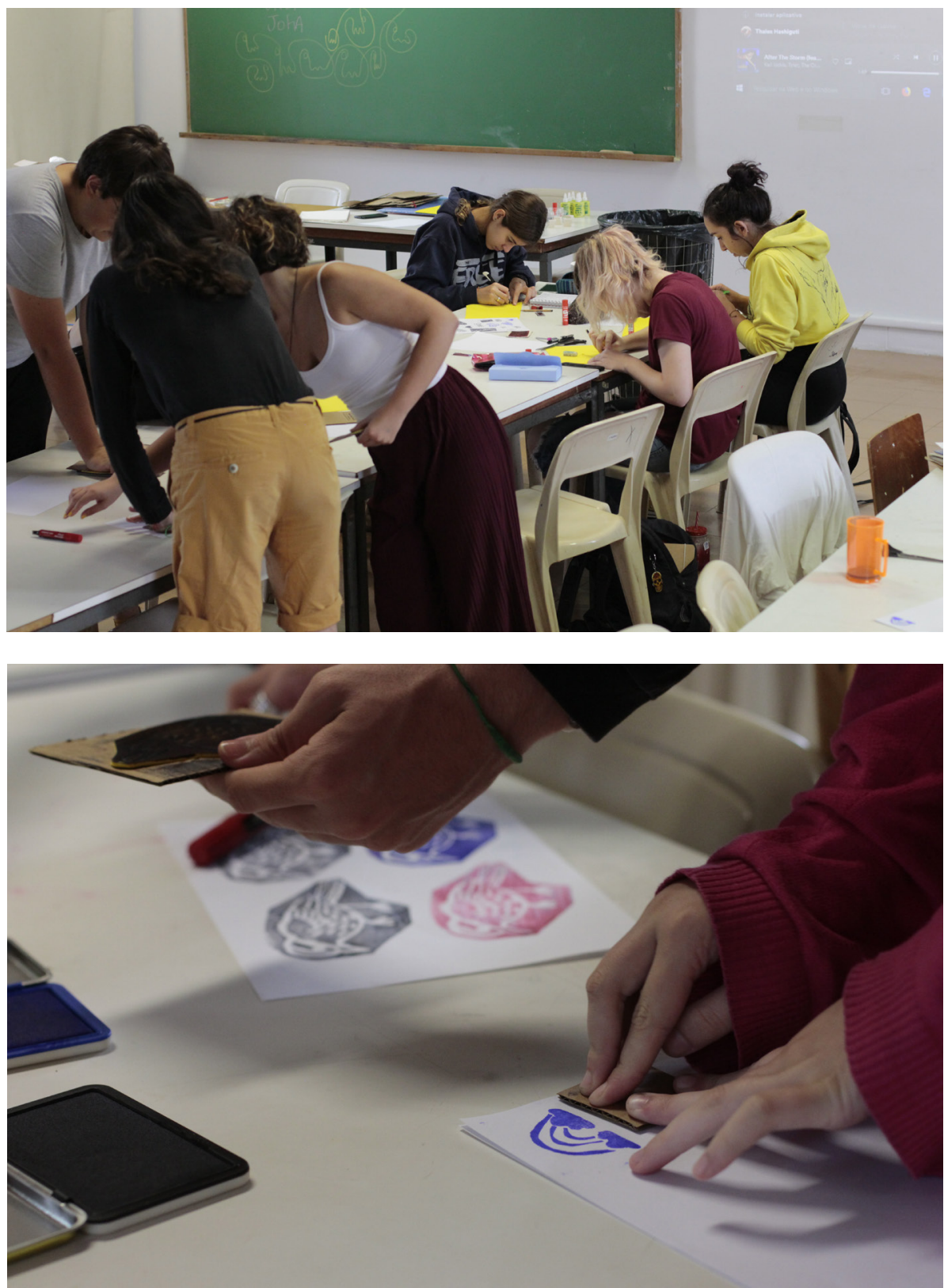

educador ou professor, mas ele também se torna um tutor onde os participantes da oficina adquirem sua própria autonomia de aprendizado e produção, pois cada um segue seu ritmo e sua linha de pesquisa a partir de uma oficina que une a todos. O participante também se torna professor a partir do momento que ele cria obras novas e diferentes resultados com as produções que cria, uma vez que o oficineiro possui seu traço e linguagem, e o participante possui outros. O que se considera desta prática arte-educativa é a esperança e possibilidade da arte e conhecimento serem (trans)passados de pessoa à pessoa, como uma rede que une cultura e educação.

\section{Referências bibliográficas}

Porto, F.D.C. (2016). Triângulo Amoroso: o uso do carimbo como dispositivo gráfico e político nas práticas artísticas do Nordeste brasileiro. Dissertação de mestrado, Universidade de São Paulo, São Paulo, SP, Brasil.

Carrión, Ulises. (1978). Rubber Stamps: Theory and Praxis (1a ed). Amsterdã: Aart van Barneveld 